\title{
Heat-induced magnetic transition accelerates redox couple mediated electrocatalytic water oxidation in alkaline media
}

\section{Duanduan Liu}

Nanjing University

Mengfei Lu

Nanjing University

Depei Liu

Nanjing University https://orcid.org/0000-0002-9933-3416

Shicheng Yan ( $\nabla$ yscfei@nju.edu.cn )

Nanjing University https://orcid.org/0000-0002-3432-9117

Wei Zhou

Tianjin University

\section{Lunyong Zhang}

MaxPlanck Institute for Chemical Physics of soild https://orcid.org/0000-0002-1193-5966

\section{Zhigang Zou}

Nanjing University

\section{Article}

Keywords: oxygen evolution reaction (OER), oxidation, catalysis, electrocatalysis

Posted Date: April 28th, 2021

DOl: https://doi.org/10.21203/rs.3.rs-428294/v1

License: (c) (i) This work is licensed under a Creative Commons Attribution 4.0 International License. Read Full License 


\section{Abstract}

The redox couple oxidation as an initial step for oxygen evolution reaction (OER) may be key for high electricity consumption in electrochemical redox couple mediated water splitting. Here, we report a heatinduced magnetic transition strategy to speed up the oxidation kinetics of redox couples. The activation energy of $\mathrm{Ni2}+/ \mathrm{Ni} 3+$ redox couple oxidation was significantly decreased by heating the $\mathrm{Ni0} .5 \mathrm{Fe} 0.50 \mathrm{xHy}$ OER catalyst above Néel temperature (TN) of $70 \mathrm{oC}$. In such a strategy, the heat in stead of electricity to overcome the spin flipping of $\mathrm{Ni} 2+/ \mathrm{Ni} 3+$ oxidation through the heat-sensitive ferrimagnetic-toparamagnetic spin state changes. The efficient heat-electricity coupling enables $\mathrm{Ni0} .5 \mathrm{Fe} 0.50 \mathrm{xHy}$ to produce the lowest OER overpotential of $170 \mathrm{mV}$ at $100 \mathrm{~mA} \mathrm{~cm}-2$ at $90 \mathrm{oC}$ in alkaline electrolyte, outperforming the benchmark IrO2 catalyst. Our findings demonstrate the application potential of heatsensitive magnetic materials in the field of electrocatalysis, which may inspire insights into designing of multi-energy complementary OER devices.

\section{Main Text}

Water electrolysis is an effective method to convert electrical energy into hydrogen energy for acquiring clean fuels from renewable energy sources ${ }^{1-3}$. However, the energy efficiency of water-splitting $\mathrm{H}_{2}$ production is limited by the high oxygen-evolution-reaction (OER) overpotentials $\mathrm{s}^{\mathbf{4} 7}$. Complementation and gain effects of different-grade energies is an efficient way to maximize the energy conversion efficiency ${ }^{8}$. A few strategies, such as magnetism-driven spin ordering ${ }^{9}$ or two-step electrochemical-chemical cycle ${ }^{10}$, were proposed to accelerate water splitting by multi-energy combination. However, it still keeps a challenge to split water by multi-energy complementation due to the lack of energy coupling mechanism.

The reliable multi-energy coupling depends strongly on clearly seeking the physical basis of the reaction. Typically, as shown in Fig. 1a, the redox couple mediated water splitting occurs via initial redox couple oxidation (rate constant, $K_{M}$ ) and subsequent OER (rate constant, $\left.K_{O E R}\right)^{11,12}$. Ideally, a highly efficient catalyst is expected to accelerate the $K_{M}$ and $K_{O E R}$ to nearly same rate, largely minimizing the oxidation potential gap $(\Delta V)$ between redox couple and OER (Fig. 1b). In theory, a magnetic redox couple may catalyze the paramagnetic oxygen release from nonmagnetic water in ground state ${ }^{13}$, which process is lower barrier compared to that the oxygen on the nonmagnetic redox couple can be generated only in an excited nonmagnetic state without violating the spin conservation rule. The two lowest ${ }^{1} \Delta_{g}$ and ${ }^{1} \Sigma_{g}$ excited states of the oxygen molecule are respectively 1 and $1.6 \mathrm{eV}$ above the ${ }^{3} \Sigma_{\mathrm{g}}$ ground state ${ }^{14}$, suggesting that catalyzing water splitting by a magnetic redox couple is thermodynamically favorite. In addition, due to that the spin conservation rule prohibits the electron transfer between species with different spin states, the spin state change driven by electricity-polarization is necessary to achieve the proton-coupled spin-related electron transfer (PCSRET) of both $\mathrm{Ni}^{2+} / \mathrm{Ni}^{3+}$ oxidation and OER, and probably are the main origination of redox couple mediated OER overpotentials. Taking the magnetic Nibased redox couple mediated OER as an example, the $K_{M}$ is limited by barriers from the PCSRET during 
$\mathrm{Ni}^{2+} / \mathrm{Ni}^{3+}$ oxidation (Fig. 1c). And the $K_{O E R}$ is restricted by PCSRET during electron injection from OER intermediates $\left({ }^{*} \mathrm{OH},{ }^{*} \mathrm{O},{ }^{*} \mathrm{OOH}\right)$ to the active catalytic species (Fig. 1d). A few theoretical results have discussed the spin-related $K_{O E R}$ on magnetic catalysts ${ }^{13,15-17}$. Although the redox couples used in water splitting, such as $\mathrm{Ni}, \mathrm{Fe}$, or $\mathrm{Co}$ ions-containing compounds ${ }^{18}$, are magnetic, to date no attention has been paid to accelerate $K_{M}$ by altering spin states. In particular, the spin-related $K_{M}$ also provided a chance to construct multi-energy coupling system if coupled non-electric energy to the electron spin changes of redox couple oxidation.

Here, we conceptually show a heat-induced magnetic transition strategy to accelerate the redox couple oxidation. We found that the activation energy of redox couple oxidation sharply decreased by contribution of heat in stead of electricity to the spin flipping. Our results show that the materials with magnetic transition sensitive to heat can promote the spin-related water splitting and the heat coupling to spin transition provides a solid physical basis to designing of multi-energy complementary OER devices.

\section{Magnetism of $\mathrm{Ni}_{0.5} \mathrm{Fe}_{0.5}(\mathrm{OH})_{2} / \mathrm{Ni}_{0.5} \mathrm{Fe}_{0.5} \mathrm{OOH}$ redox couple}

We select the magnetic $\mathrm{Ni}_{\mathrm{x}} \mathrm{Fe}_{1-\mathrm{x}}(\mathrm{OH})_{2}$ with inherently high $K_{O E R}$ and frustrated $K_{M}$ as model material to show the magnetic transition awakened heat-electricity coupling strategy. We first optimized the $\mathrm{Fe}$ content relative to $\mathrm{Ni}$ (Supplementary Fig. 1). A highest OER current density was obtained in $a$ $\mathrm{Ni}_{\mathrm{x}} \mathrm{Fe}_{1-\mathrm{x}}(\mathrm{OH})_{2}$ with Ni:Fe = 1:1 [denoted as $\mathrm{Ni}_{0.5} \mathrm{Fe}_{0.5}(\mathrm{OH})_{2}$ ], in good agreement with the previous report ${ }^{19}$. The electrochemically deposited low-crystallinity $a-\mathrm{Ni}_{0.5} \mathrm{Fe}_{0.5}(\mathrm{OH})_{2}$ onto $\mathrm{Ni}$ foam (see Methods for the detailed procedure) was confirmed by XRD and high-resolution TEM and exhibited highest OER activity (Supplementary Fig. 2). The $\alpha-\mathrm{Ni}_{0.5} \mathrm{Fe}_{0.5}(\mathrm{OH})_{2} / \gamma-\mathrm{Ni}_{0.5} \mathrm{Fe}_{0.5} \mathrm{OOH}$ dual-phase mixture $\left(\mathrm{Ni}_{0.5} \mathrm{Fe}_{0.5} \mathrm{O}_{\mathrm{x}} \mathrm{H}_{\mathrm{y}}\right)$ was created at $1.41 \mathrm{~V}$ at $30{ }^{\circ} \mathrm{C}$ to describe the $\mathrm{Ni}^{2+} / \mathrm{Ni}^{3+}$ redox couple. We first performed the spin-polarized density functional theory (DFT) calculations to disclose the magnetic ground states of a- $\mathrm{Ni}_{0.5} \mathrm{Fe}_{0.5}(\mathrm{OH})_{2}$ and $y-\mathrm{Ni}_{0.5} \mathrm{Fe}_{0.5} \mathrm{OOH}$. The calculated total density of states (DOS) suggested that $\mathrm{Ni}_{0.5} \mathrm{Fe}_{0.5}(\mathrm{OH})_{2}$ is semiconductor-like, which hosts a valence band near the Fermi level dominated by the spin-down Fe 3d orbits and a conductive band originating from asymmetric spin-up Ni 3d and spin-down Fe $3 \mathrm{~d}$ states as seen from the projected DOS (Fig. 2a). In contrast, $\mathrm{Ni}_{0.5} \mathrm{Fe}_{0.5} \mathrm{OOH}$ is metal-like with asymmetric spin-down $\mathrm{Ni} 3 \mathrm{~d}$ and spin-up Fe 3d orbits around the Fermi level, implying an easier electron transfer in $\mathrm{Ni}_{0.5} \mathrm{Fe}_{0.5} \mathrm{OOH}$. Integration of the spin projected DOS of $\mathrm{Fe}$ and $\mathrm{Ni}$ indicated that the two materials are ferrimagnetic at $0 \mathrm{~K}$ with a magnetic moment of $2 \mu \mathrm{B}$ per formula unit for $\mathrm{Ni}_{0.5} \mathrm{Fe}_{0.5}(\mathrm{OH})_{2}$ and $4.62 \mu \mathrm{B}$ per formula unit for $\mathrm{Ni}_{0.5} \mathrm{Fe}_{0.5} \mathrm{OOH}$. The ferrimagnetic states are originated from double exchange interaction of Fe-O-Ni configurations.

The magnetic properties were further analyzed by using a superconducting quantum interface device (SQUID) magnetometer in their thermally stable region of 200-500K (Supplementary Fig. 3). The zero-field cooled (ZFC) and field cooled (FC) scanning under an applied magnetic field $\mathrm{H}=500$ Oe showed a moment as a function of temperature and a splitting between the ZFC and FC traces at low temperature 
for both $\mathrm{Ni}_{0.5} \mathrm{Fe}_{0.5}(\mathrm{OH})_{2}$ and $\mathrm{Ni}_{0.5} \mathrm{Fe}_{0.5} \mathrm{O}_{\mathrm{x}} \mathrm{H}_{\mathrm{y}}$, identifying paramagnetic-to-ferrimagnetic transition with a $\mathrm{T}_{\mathrm{N}}$ of $104{ }^{\circ} \mathrm{C}$ for $\mathrm{Ni}_{0.5} \mathrm{Fe}_{0.5}(\mathrm{OH})_{2}$ and $70{ }^{\circ} \mathrm{C}$ for $\mathrm{Ni}_{0.5} \mathrm{Fe}_{0.5} \mathrm{O}_{\mathrm{x}} \mathrm{H}_{\mathrm{y}}$ (Fig. 2b), in agreement with the predictions of DFT calculations. The $\mathrm{T}_{\mathrm{N}}\left(53^{\circ} \mathrm{C}\right)$ of pure $\mathrm{Ni}(\mathrm{OH})_{2}$ is obviously lower than that of $\mathrm{Ni}_{0.5} \mathrm{Fe}_{0.5}(\mathrm{OH})_{2}$ (Supplementary Fig. 4), revealing that Fe doping enhances the spin antiparallel interaction (ferrimagnetism) and so makes the spin state change difficult with heating. This verified that the $\mathrm{Fe}$ doping stabilized the high-spin $\mathrm{Ni}^{2+}$ with of electronic configuration $t_{2 g}{ }^{6} e_{g}{ }^{2}$ in $\mathrm{Ni}_{0.5} \mathrm{Fe}_{0.5}(\mathrm{OH})_{2}$. The $\mathrm{Ni}_{0.5} \mathrm{Fe}_{0.5}(\mathrm{OH})_{2}$ exhibited a wide ferrimagnetic-paramagnetic transition temperature region covering the room temperature, probably implying various local structures (magnetic states) in low-crystalline $\mathrm{Ni}_{0.5} \mathrm{Fe}_{0.5}(\mathrm{OH})_{2}$ with different susceptibility to temperature variation. After electrochemical oxidation of $\mathrm{Ni}_{0.5} \mathrm{Fe}_{0.5}(\mathrm{OH})_{2}$ to $\mathrm{Ni}_{0.5} \mathrm{Fe}_{0.5} \mathrm{O}_{\mathrm{x}} \mathrm{H}_{\mathrm{y}}$, the sharply decreased $\mathrm{T}_{\mathrm{N}}$ would be a result of the decreased crystallinity of $\mathrm{Ni}_{0.5} \mathrm{Fe}_{0.5}(\mathrm{OH})_{2}$ due to the formation of amorphous $\mathrm{Ni}_{0.5} \mathrm{Fe}_{0.5} \mathrm{OOH}$ (Supplementary Fig. 5). Both $\mathrm{Ni}_{0.5} \mathrm{Fe}_{0.5}(\mathrm{OH})_{2}$ and $\mathrm{Ni}_{0.5} \mathrm{Fe}_{0.5} \mathrm{O}_{\mathrm{x}} \mathrm{H}_{\mathrm{y}}$ showed typical hysteresis loops with remnant magnetization at zero magnetic field at $200 \mathrm{~K}$ and $300 \mathrm{~K}$ (Fig. 2c), confirming the ferrimagnetism at $\mathrm{T}<\mathrm{T}_{\mathrm{N}}$. In contrast, at $\mathrm{T}>\mathrm{T}_{\mathrm{N}}$, $450 \mathrm{~K}$, the $\mathrm{M}-\mathrm{H}$ curves are zero-crossing lines without loop, which is assigned to totally paramagnetic state.

\section{Heatelectricity coupling $\mathrm{Ni}_{0.5} \mathrm{Fe}_{0.5}(\mathrm{OH})_{2} / \mathrm{Ni}_{0.5} \mathrm{Fe}_{0.5} \mathrm{OOH}$ oxidation}

The low $\mathrm{T}_{\mathrm{N}}$ of $\mathrm{Ni}_{0.5} \mathrm{Fe}_{0.5} \mathrm{O}_{\mathrm{x}} \mathrm{H}_{\mathrm{y}}, 70^{\circ} \mathrm{C}$, inspired us to design a heat-electricity coupling water splitting system, aiming to trigger the spin state change of $\mathrm{Ni}^{2+} / \mathrm{Ni}^{3+}$ oxidation by the low-grade heat $\left(<100{ }^{\circ} \mathrm{C}\right)$ instead of electricity. To check the efforts of heat-electricity coupling, the temperature-dependent linear sweep voltammetrys (LSV) of $\mathrm{Ni}_{0.5} \mathrm{Fe}_{0.5}(\mathrm{OH})_{2}$ films were acquired in $1 \mathrm{M} \mathrm{KOH}$ solution (Fig. 3a). A high oxidation wave in LSV curves occurs first and can be assigned to the $\mathrm{Ni}^{2+} / \mathrm{Ni}^{3+}$ oxidation, indicating the frustrated $K_{M}$. To avoid the ion redox region, the potential $\left(V_{100}\right)$ and overpotential $\left(\eta_{100}\right)$ at $100 \mathrm{~mA} \mathrm{~cm}^{-2}$ were used to describe the temperature dependence of OER activity. Obviously, the $V_{100}$ at $30^{\circ} \mathrm{C}$ is greatly smaller for $\mathrm{Ni}_{0.5} \mathrm{Fe}_{0.5}(\mathrm{OH})_{2}(1.46 \mathrm{~V})$ than $\mathrm{Ni}(\mathrm{OH})_{2}(1.63 \mathrm{~V})$, suggesting significant contributions of $\mathrm{Fe}$ doping to the OER activity of $\mathrm{Ni}(\mathrm{OH})_{2}$ (Supplementary Fig. 6a). With elevating temperatures from 30 to 90 ${ }^{\circ} \mathrm{C}$, the OER current-voltage curves of $\mathrm{Ni}_{0.5} \mathrm{Fe}_{0.5}(\mathrm{OH})_{2}$ parallelly moved forwards to the more negative potentials, significantly outperforming the nonmagnetic benchmark $\mathrm{IrO}_{2}$ catalyst at each temperatures (Supplementary Fig. 6b). The nearly constant slope of current-voltage curves (Fig.3a and Supplementary Fig. 7a) suggested that the Fe doping significantly promoted the OER kinetics at such a rate that is completely diffusion-limited, revealing that the low-grade heat does not impose on $K_{O E R}$ but on the $K_{M}$. A noticeable phenomenon is that for $\mathrm{Ni}_{0.5} \mathrm{Fe}_{0.5}(\mathrm{OH})_{2}$ the $\Delta V$ was gradually minimized with increasing temperature, suggesting that $K_{M}$ and $K_{O E R}$ gradually tend to be equal. The $V_{100}$ was parallelly moved from $1.46 \mathrm{~V}$ at $30^{\circ} \mathrm{C}$ to $1.40 \mathrm{~V}$ at $90^{\circ} \mathrm{C}$, corresponding to a low $\eta_{100}$ of $170 \mathrm{mV}$. The $60 \mathrm{mV}$ decrease in OER overpotential would be a result of accelerated $\mathrm{Ni}^{2+} / \mathrm{Ni}^{3+}$ oxidation kinetics, $K_{M}$ whose activation energy was successfully awakened by heat field. In contrast, the Tafel slope of pure $\mathrm{Ni}(\mathrm{OH})_{2}$ is temperature- 
dependent, varying from $105 \mathrm{mV} \mathrm{dec}{ }^{-1}$ at $30^{\circ} \mathrm{C}$ to $74 \mathrm{mV} \mathrm{dec}^{-1}$ at $90^{\circ} \mathrm{C}$ (Supplementary Fig. $7 \mathrm{~b}$ ), confirming that the water oxidation on $\mathrm{Ni}(\mathrm{OH})_{2}$ without the help of $\mathrm{Fe}$ is mainly limited by its sluggish OER kinetics.

The logarithm of peak current of $\mathrm{Ni}^{2+} / \mathrm{Ni}^{3+}$ oxidation for $\mathrm{Ni}_{0.5} \mathrm{Fe}_{0.5} \mathrm{O}_{x} \mathrm{H}_{\mathrm{y}}$ exhibited a non-linear Arrhenius relationship responsive to the temperature changes and can be fitted into two apparent activation energies ( $Q_{M^{\prime}}$ Fig. 3b): $6.33 \mathrm{~kJ} \cdot \mathrm{mol}^{-1}$ at $\mathrm{T}<\mathrm{T}_{\mathrm{N}}$ and $2.79 \mathrm{~kJ} \cdot \mathrm{mol}^{-1}$ at $\mathrm{T}>\mathrm{T}_{\mathrm{N}}$. Correspondingly, the $\Delta \mathrm{V}$ is sharply narrowed at $\mathrm{T}>\mathrm{T}_{\mathrm{N}}$. This result means that the paramagnetic $\mathrm{Ni}^{2+} / \mathrm{Ni}^{3+}$ oxidation is a heatelectricity coupling process with decreased electron transfer barrier. The temperature dependence of electron transfer during $\mathrm{Ni}^{2+} / \mathrm{Ni}^{3+}$ oxidation was further investigated by electrochemical impedance spectroscopy (EIS, Fig. 3c). The Nyquist plots were recorded at $1.4 \mathrm{~V}$, a peak potential of $\mathrm{Ni}^{2+} \mathrm{Ni}^{3+}$ oxidation. The irregular semicircles in Nyquist plots allowed us decoupling the $\mathrm{Ni}^{2+} / \mathrm{Ni}^{3+}$ and OER processes using a Randle's equivalent circuit, which was composed of electrolyte-catalyst electrical connection resistance $\left(R_{s}\right)$, and electron transfer resistance and capacitance for $\mathrm{Ni}^{2+} / \mathrm{Ni}^{3+}$ oxidation $\left(\mathrm{R}_{c t, M}\right.$, $\left.\mathrm{C}_{\mathrm{M}}\right)$ and $\mathrm{OER}\left(\mathrm{R}_{\mathrm{Ct}, \mathrm{OER}}, \mathrm{C}_{\mathrm{OER}}\right)$. As listed in Supplementary Table 1 , the $\mathrm{R}_{\mathrm{Ct}, \mathrm{M}}$ significantly reduced at temperatures above $T_{N}$, well corresponding to the lower $Q_{M}$. This fact verified the low electron transfer barriers between paramagnetic $\mathrm{Ni}_{0.5} \mathrm{Fe}_{0.5}(\mathrm{OH})_{2}$ and $\mathrm{Ni}_{0.5} \mathrm{Fe}_{0.5} \mathrm{OOH}$ due to no need of spin flipping. At $1.4 \mathrm{~V}$, no OER faradaic efficiency was detected at $40^{\circ} \mathrm{C}$. However, at $90^{\circ} \mathrm{C}, 59.2 \%$ and $53 \%$ faradaic efficiency for the $\mathrm{H}_{2}$ and $\mathrm{O}_{2}$ evolution, respectively, experimented that the heat coupling to $\mathrm{Ni}^{2+} / \mathrm{Ni}^{3+}$ instead of electricity enabled the occurrence of OER at lower potentials (Supplementary Table 2 and Supplementary Fig. 8). At 1.45V (Supplementary Fig. 9), the OER region, $R_{C t, O E R}$ and $C_{O E R}$ are nearly constant independently of temperature change, verifying the high OER activity of $\mathrm{Ni}_{0.5} \mathrm{Fe}_{0.5} \mathrm{OOH}$, as well confirmed by the constant electrochemical avtive surface area (Supplementary Fig. 10). However, at $T \otimes T_{N}$, the closely equal $\mathrm{R}_{\mathrm{ct}, \mathrm{M}}$ and $\mathrm{R}_{\mathrm{Ct}, \mathrm{OER}}$ confirmed that the $K_{M}$ and $K_{O E R}$ keep nearly same rate. The slightly high $\mathrm{R}_{\mathrm{ct}, \mathrm{M}}$ would be the origination of the small residual $\Delta V$ due to the semiconducting $\mathrm{Ni}_{0.5} \mathrm{Fe}_{0.5}(\mathrm{OH})_{2}$ with large resistance. Indeed, owing to the limited diffusion depth of OER intermediates in catalyst particles, the core parts of $\mathrm{Ni}_{0.5} \mathrm{Fe}_{0.5}(\mathrm{OH})_{2}$ particles are not able to participate OER process, thus contributing the partial potential drop.

Owing to the structural distortion and low structural symmetry, the total energy difference between ferrimagnetic and paramagnetic $\mathrm{Ni}_{0.5} \mathrm{Fe}_{0.5} \mathrm{OOH}$ is small (about 30 meV by DFT calculations). And the free energy change for oxidation of ferrimagnetic $\mathrm{Ni}_{0.5} \mathrm{Fe}_{0.5}(\mathrm{OH})_{2}$ into ferrimagnetic or paramagnetic $\mathrm{Ni}_{0.5} \mathrm{Fe}_{0.5} \mathrm{OOH}$ was similar (Supplementary Fig. 11 ), implying that the paramagnetic $\mathrm{Ni}_{0.5} \mathrm{Fe}_{0.5} \mathrm{OOH}$ could be expected during $\mathrm{OER}$, although exhibiting ferrimagnetic ground state at $0 \mathrm{~K}$. Indeed, the free energy profiles demonstrated that the overpotential $(\eta)$ of rate-determining step to form ${ }^{*} \mathrm{O}$ via ${ }^{*} \mathrm{OH}$ is significantly lower for paramagnetic $\mathrm{Ni}_{0.5} \mathrm{Fe}_{0.5} \mathrm{OOH}(0.56 \mathrm{eV})$ than the ferrimagnetic $\mathrm{Ni}_{0.5} \mathrm{Fe}_{0.5} \mathrm{OOH}(1.64 \mathrm{eV}$, Fig. 3d). This result would further suggest the oxidation of ferrimagnetic $\mathrm{Ni}_{0.5} \mathrm{Fe}_{0.5}(\mathrm{OH})_{2}$ to produce the paramagnetic $\mathrm{Ni}_{0.5} \mathrm{Fe}_{0.5} \mathrm{OOH}$, a magnetic state affording high enough $K_{O E R}$ independently of temperature 
change. That is, the frustrated $K_{M}$ is a result of spin flipping when $T<\mathrm{T}_{\mathrm{N}}$. Indeed, the DFT calculations indicated that the phase transition from paramagnetic $\mathrm{Ni}_{0.5} \mathrm{Fe}_{0.5}(\mathrm{OH})_{2}$ to paramagnetic $\mathrm{Ni}_{0.5} \mathrm{Fe}_{0.5} \mathrm{OOH}$ is thermodynamically favourite (Supplementary Fig. 11), clearly concluding that the spin flipping is high electricity consumption process. In fact, at $T \otimes \mathrm{T}_{\mathrm{N}}$ (Fig. 3a), the obviously decreased onset of $\mathrm{Ni}^{2+} / \mathrm{Ni}^{3+}$ oxidation $\left(1.36 \mathrm{~V}\right.$ at $30-70{ }^{\circ} \mathrm{C}$ and $1.35 \mathrm{~V}$ at $\left.70-90^{\circ} \mathrm{C}\right)$ confirmed that the heat indeed builds the low- $Q_{M}$ process for paramagnetic $\mathrm{Ni}_{0.5} \mathrm{Fe}_{0.5}(\mathrm{OH})_{2}$ / paramagnetic $\mathrm{Ni}_{0.5} \mathrm{Fe}_{0.5} \mathrm{OOH}$ electrochemical oxidation without spin flipping, realizing by the heat driving ferrimagnetic-paramagnetic transition of $\mathrm{Ni}_{0.5} \mathrm{Fe}_{0.5}(\mathrm{OH})_{2}$.

\section{Spectroscopic evidences to $\mathrm{Ni}^{2+} / \mathrm{Ni}^{3+}$ kinetics}

XPS and Raman spectroscopy were collected to visualize the heat-electricity coupling driven active species evolution during $\mathrm{Ni}^{2+} / \mathrm{Ni}^{3+}$ oxidation and OER. To avoid the influences from $\mathrm{Ni}$ foam, the $\mathrm{Ni}_{0.5} \mathrm{Fe}_{0.5}(\mathrm{OH})_{2}$ was deposited on carbon fiber paper. A slight increase in the peak oxidation potential (at $1.46 \mathrm{~V}$ ) of $\mathrm{Ni}^{2+} / \mathrm{Ni}^{3+}$ was from the electrical conductivity differences between conductive substrates (Supplementary Fig. 12). As shown in Fig. $4 \mathrm{a}$ and b, Ni $2 \mathrm{p}$ core-level XPS analysis on raw $\mathrm{Ni}_{0.5} \mathrm{Fe}_{0.5}(\mathrm{OH})_{2}$ indicated the binding energy at $855.5 \mathrm{eV}$ with a satellite peak at $861.3 \mathrm{eV}$ for $\mathrm{Ni}^{2+} 2 \mathrm{p}_{3 / 2}$ in $a-\mathrm{Ni}(\mathrm{OH})_{2}{ }^{20}$. And the Fe $2 p$ core-level XPS exhibited a binding energy at $711.7 \mathrm{eV}$ for $\mathrm{Fe}^{3+} 2 \mathrm{p}_{3 / 2}$ in $a-\mathrm{FeOOH}^{21}$ (Fig. 4b). Raman bands (Fig. 4c) of raw $\mathrm{Ni}_{0.5} \mathrm{Fe}_{0.5}(\mathrm{OH})_{2}$ at 455 and $543 \mathrm{~cm}^{-}$were assigned to the $\alpha-\mathrm{Ni}(\mathrm{OH})_{2}$ species ${ }^{22}$ and the Raman peaks located at 200,310, 476, and $678 \mathrm{~cm}^{-1}$ can be assigned to the $\alpha$-FeOOH species ${ }^{23}$. After oxidizing $\mathrm{Ni}_{0.5} \mathrm{Fe}_{0.5}(\mathrm{OH})_{2}$ at $1.45 \mathrm{~V}$ and $40{ }^{\circ} \mathrm{C}, 0.31 \mathrm{eV}$ increase in the Ni $2 \mathrm{p}$ XPS binding energy indicated the formation of high-valence $\mathrm{Ni}^{\delta+}(\delta>2)$, and Raman bands of the $\gamma$-NiOOH species were observed at $473 \mathrm{~cm}^{-1}$ (depolarized $\mathrm{E}_{\mathrm{g}}$ mode, bending) and $557 \mathrm{~cm}^{-}$(polarized $\mathrm{A} 1_{\mathrm{g}}$ mode, stretching) ${ }^{24}$, and the $455 \mathrm{~cm}^{-}$for $\mathrm{Ni}^{2+}-\mathrm{OH}$ species $\left(\mathrm{A}_{1 \mathrm{~g}}\right)$ was also visible due to the $\mathrm{Ni}_{0.5} \mathrm{Fe}_{0.5}(\mathrm{OH})_{2} / \mathrm{Ni}_{0.5} \mathrm{Fe}_{0.5} \mathrm{OOH}$ coexistence, suggesting the sluggish ferrimagnetic $\mathrm{Ni}^{2+} /$ paramagnetic $\mathrm{Ni}^{3+}$ oxidation kinetics at low temperatures. Evidently, after introducing $\mathrm{Fe}$, the $\mathrm{Ni}^{2+} / \mathrm{Ni}^{3+}$ redox peak shifted by $\sim 60 \mathrm{mV}$ from $+1.34 \mathrm{~V}$ to $+1.40 \mathrm{~V}$ (Supplementary Fig. 6 ) at $30^{\circ} \mathrm{C}$, in good agreement with the previous reports ${ }^{19}$. A projected density of states (pDOS) analysis (Fig. 2 and Supplementary Fig. 13) revealed that Ni 3d states near the Fermi level of $\mathrm{Ni}(\mathrm{OH})_{2}$ were significantly modified by Fe 3d orbits. The strong $d$-d interactions between Fe $3 \mathrm{~d}$ and $\mathrm{Ni} 3 \mathrm{~d}$ orbits make the $\mathrm{Ni} 3 \mathrm{~d}$ states far from the Fermi level, thus sharply increasing the barrier for extracting electrons from $\mathrm{Ni}$ sites of $\mathrm{Fe}_{0.5} \mathrm{Ni}_{0.5}(\mathrm{OH})_{2}$. This means that the higher potential was demanded to drive $\mathrm{Ni}^{2+} / \mathrm{Ni}^{3+}$ oxidation, as demonstrated by the obvious increase in $\mathrm{T}_{\mathrm{N}}$ which is proportional to the double exchange interactions of Fe-O-Ni configurations. Therefore, we can conclude that although $\mathrm{Fe}$ doping significantly improves the OER kinetics, the $\mathrm{Ni}^{2+} / \mathrm{Ni}^{3+}$ oxidation kinetics were depressed. However, at $\mathrm{T}>70^{\circ} \mathrm{C}$, only the $\mathrm{Ni}^{2+}$ species was detected in both the XPS and Raman spectra, verifying the easy paramagnetic $\mathrm{Ni}^{2+} / \mathrm{Ni}^{3+}$ redox cycling without spin flipping. In this situation, the energy requirement in spin flipping was completely provided by heat, thus largely accelerating the $K_{M}$ to achieve the nearly same rate with $\mathrm{K}_{\mathrm{OER}}$ due to the effective heat-electricity coupling. We also detected the $\mathrm{Ni}^{2+}$ species at the OER 
potential region at $T<T_{N}$ (Supplementary Fig. 14), further demonstrating that accelerating $K_{M}$ is a result of overcoming the high $\mathrm{Ni}^{2+} / \mathrm{Ni}^{3+}$ oxidation barrier by heat-induced spin flipping or increasing applied potential.

\section{Nature of high OER activity and physical basis of heat-electricity coupling}

In particular, at $1.45 \mathrm{~V}$ and $90^{\circ} \mathrm{C}$, the OER process occurs and about $1.0 \mathrm{eV}$ increase in binding energy of Fe $2 p$ showed that Fe sites may be the OER active sites. Many efforts have been paid on distinguishing whether nickel ${ }^{25,26}$, iron ${ }^{27-29}$, or the synergy of nickel and iron sites ${ }^{30}$ are the active centers, mainly focusing on detection of high-valence Fe or Ni species without attention to quantum spin(-orbital) exchange interactions (QSEI). Spin-polarized DFT results exhibited that all the OER intermediates $\left({ }^{*} \mathrm{OH},{ }^{*} \mathrm{O}\right.$, ${ }^{*} \mathrm{OOH}$ ) tend to adsorb onto Fe sites (Fig.3d). The OER activity difference between paramagnetic and ferrimagnetic $\mathrm{Ni}_{0.5} \mathrm{Fe}_{0.5} \mathrm{OOH}$ originated from the downshift of Fermi level of paramagnetic $\mathrm{Ni}_{0.5} \mathrm{Fe}_{0.5} \mathrm{OOH}$ (Fig. 5a), hence reducing the electron transfer barrier due to narrowing of the energy difference between Fermi level of catalyst and the bonding orbital level composing of $d-p$ orbital hybrid of Fe $3 d$ active species and 02p OER intermediates. Charge population analysis indicated that the Fe sites in both ferrimagnetic and paramagnetic $\mathrm{Ni}_{0.5} \mathrm{Fe}_{0.5} \mathrm{OOH}$ are more effective electron transfer pathway (Fig. $5 \mathrm{~b}$ ). The underperformance in electron transfer for adsorption of ${ }^{*} \mathrm{OH}$ implied that the OER rate-determining step to form ${ }^{*} \mathrm{O}$ on $\mathrm{Ni}_{0.5} \mathrm{Fe}_{0.5} \mathrm{OOH}$ resulted from the weak interactions between $\mathrm{Fe}$ sites and ${ }^{*} \mathrm{OH}$ species. For adsorption of ${ }^{*} \mathrm{O}$, the effective electron transfer from ${ }^{*} \mathrm{O}$ to metal sites may suggest a fact that the electron from OER intermediates first injected to $\mathrm{Fe} 3 \mathrm{~d}$ via the $\mathrm{Fe} 3 \mathrm{~d}-\mathrm{O} 2 \mathrm{p}$ bonding orbitals and then extracted to external circuit via Fe-O-Ni double exchange interactions.

The EPR spectra were recorded to examine the spin states of $\mathrm{Fe}^{3+}$ ions (Fig. 5c). The total spectrum was simulated by using a standard line-shape model with anisotropic g-factor (WINEPR). The simulated results indicated that the paramagnetic EPR signal originates from the low-spin $\mathrm{Fe}^{3+}(\mathrm{S}=1 / 2)$ with $\mathrm{g}_{1}=$ 2.9790, $g_{2}=2.0052$, and $g_{3}=1.9312$ for $\mathrm{Ni}_{0.5} \mathrm{Fe}_{0.5}(\mathrm{OH})_{2}$ and $\mathrm{g}_{1}=2.9720, \mathrm{~g}_{2}=2.0051$, and $\mathrm{g}_{3}=1.8510$ for $\mathrm{Ni}_{0.5} \mathrm{Fe}_{0.5} \mathrm{O}_{\mathrm{x}} \mathrm{H}_{\mathrm{y}}{ }^{31}$. This evidence implied that at least partial $\mathrm{Fe}^{3+}$ sites in $\mathrm{Fe}-\mathrm{O}-\mathrm{Ni}$ configurations are lowspin paramagnetic at room temperature (ions in ferrimagnetic state only contribute to widening of the EPR line width due to the strong spin-spin interaction). The low spin state of $\mathrm{Fe}^{3+}$ exhibited the spin distribution composing of the unoccupied $e_{g}$ orbitals and the incompletely occupied $t_{2 g}$ with one unpaired single-spin electron (Fig. 5d). In contrast, the low spin configuration of $\mathrm{Ni}^{3+}$ only has incompletely occupied $e_{g}$ orbitals. The more electron transfer channels enable the $\mathrm{Fe}^{3+}$ sites to be a strong electron acceptor, thus exhibiting a strong interactions with the OER intermediates.

Here, as shown in Fig. $5 \mathrm{e}$, we can conclude that the $\mathrm{Ni}_{0.5} \mathrm{Fe}_{0.5} \mathrm{O}_{\mathrm{x}} \mathrm{H}_{\mathrm{y}}$ is ferrimagnetic-to-paramagnetic transition sensitive to low-grade heat, thus achieving a low electron transfer barrier for $\mathrm{Ni}^{2+} / \mathrm{Ni}^{3+}$ oxidation by paramagnetic $\mathrm{Ni}_{0.5} \mathrm{Fe}_{0.5}(\mathrm{OH})_{2} / \mathrm{Ni}_{0.5} \mathrm{Fe}_{0.5} \mathrm{OOH}$ phase transition at above $\mathrm{T}_{\mathrm{N}}$. The heat is consequently coupled to be responsible for spin flipping, effectively replacing electricity consumation. In addition, in the 
paramagnetic situation without spin flipping, the low-spin $\mathrm{Fe}^{3+}$ with more electron transfer channels are more beneficial to the double exchange interaction of Fe-O-Ni configurations in $\mathrm{Ni}^{2+} / \mathrm{Ni}^{3+}$ oxidation and electron transfer in OER process, thus significantly accelerating the redox couple mediated water splitting with nearly same $K_{M}$ and $K_{O E R}$.

In summary, the heat-induced magnetic transition was conceptually verified to be effective to construct a heat-electricity synergistic water splitting system. As an example, the $\mathrm{Ni}^{2+} / \mathrm{Ni}^{3+}$ cycling kinetics in the $\mathrm{Ni}$ based redox couple mediated water splitting, an initial OER bottleneck step, was significantly accelerated by coupling heat to the electricity-driven $\mathrm{Ni}^{2+} / \mathrm{Ni}^{3+}$ redox cycling. Based on the spectroscopic and magnetic tests, we showed here a clear physical mechanism of heat-electricity coupling water splitting with the assistance of magnetic phase transition. The low-grade thermal field $\left(<100^{\circ} \mathrm{C}\right)$ instead of electricity was attributed to the thermally sensitive ferrimagnetic-to-paramagnetic spin state change of $\mathrm{Ni}^{2+} / \mathrm{Ni}^{3+}$ redox cycling. Our results provide a new possibility to utilize various heat sources, such as that produced via industrial, solar-thermal or geothermal processes, by introducing magnetic state modulation, to design multi-energy complementary OER devices.

\section{Methods}

Theoretical calculations. The structural model of $a-\mathrm{Ni}(\mathrm{OH})_{2}$ was derived from Ref. $32^{32}$ which belongs to a space group of $\mathrm{P}-3 \mathrm{~m} 1$. The structural model of $\gamma-\mathrm{NiOOH}$ was constructed by deprotonating $\beta$-NiOOH to produce $\mathrm{Ni}$ oxidation state of +3 (taken from Ref. $3^{33}$ ). And Fe doping concentration of $50 \%$ was set for $\mathrm{Fe}_{0.5} \mathrm{Ni}_{0.5}(\mathrm{OH})_{2}$ and $\mathrm{Fe}_{0.5} \mathrm{Ni}_{0.5} \mathrm{OOH}$ phases based on the experimental results. As for the OER calculations, the edge models were constructed and the exposed oxygen atoms at surface were passivated by hydrogen atoms

All calculations were performed with Vienna Ab initio Simulation Package (VASP) based on the densityfunctional theory (DFT) ${ }^{34}$. The generalized gradient approximation (GGA) with PBE functional was used for the exchange-correlation energy, and DFT-D2 method proposed by Grimme was adopted for van der Waals interactions ${ }^{35}$. A plane-wave expansion for the basis set with a cutoff energy of $400 \mathrm{eV}$ was employed here. The gamma centered $1 \times 1 \times 1 k$-point meshes was used for the Brillouin-zone integration of supercell models. All atoms are fully relaxed until the energy convergence and residual force was less than $10^{-5} \mathrm{eV}$ and $0.02 \mathrm{eV} / \AA$, respectively. To eliminate interactions between the neighboring cells, vacuum regions of $16 \AA$ were used for the OER surface model. Moreover, considering the strong correlation effect of $\mathrm{d}$ orbital in transition metals, the $\mathrm{U}$ value of $5.0 \mathrm{eV}$ and $6.6 \mathrm{eV}$ were chosen for $\mathrm{d}$ electrons of $\mathrm{Ni}$ and $\mathrm{Fe}$ atoms.

To determine the free energy of intermediates at the surface of catalyst $\left(G^{\star}\right)$ during the OER process, equations below were employed here: 


$$
\begin{aligned}
& \mathrm{G}_{\mathrm{OH}^{*}}=\left(\mathrm{E}_{\mathrm{OH}^{*}}+0.5 \times E_{\mathrm{H}_{2}}-\mathrm{E}_{\mathrm{H}_{2} \mathrm{O}}-\mathrm{E}_{*}\right)+\left(\mathrm{ZPE}_{\mathrm{OH}^{*}}+0.5 \times \mathrm{ZPE}_{\mathrm{H}_{2}}-\mathrm{ZPE}_{\mathrm{H}_{2} \mathrm{O}}-\mathrm{ZPE} \mathrm{E}_{*}\right)- \\
& \mathrm{T} \times\left(\mathrm{S}_{\mathrm{OH}^{*}}+0.5 \times \mathrm{S}_{\mathrm{H} 2}-\mathrm{S}_{\mathrm{H}_{2} \mathrm{O}}-\mathrm{S}_{*}\right) \\
& \mathrm{G}_{\mathrm{O}^{*}}=\left(\mathrm{E}_{\mathrm{O}^{*}}+\mathrm{E}_{\mathrm{H} 2}-\mathrm{E}_{\mathrm{H}_{2} \mathrm{O}}-\mathrm{E}_{*}\right)+\left(\mathrm{ZPE}_{\mathrm{O}^{*}}+\mathrm{ZPE}_{\mathrm{H}_{2}}-\mathrm{ZPE}_{\mathrm{H}_{2} \mathrm{O}}-\mathrm{ZPE} \mathrm{E}_{*}\right)- \\
& \mathrm{T} \times\left(\mathrm{S}_{\mathrm{O}}+\mathrm{S}_{\mathrm{H} 2}-\mathrm{S}_{\mathrm{H} 2} \mathrm{O}-\mathrm{S}_{*}\right) \\
& \mathrm{G}_{\mathrm{OOH}^{*}}=\left(\mathrm{E}_{\mathrm{OOH}^{*}}+1.5 \times \mathrm{E}_{\mathrm{H}_{2}}-2 \times \mathrm{E}_{\mathrm{H} 2 \mathrm{O}}-\mathrm{E}_{*}\right)+\left(\mathrm{ZPE}_{\mathrm{OOH}^{*}}+1.5 \times \mathrm{ZPE}_{\mathrm{H}_{2}}-2 \times \mathrm{ZPE}_{\mathrm{H}_{2} \mathrm{O}}-\mathrm{ZPE}\right)- \\
& \mathrm{T} \times\left(\mathrm{S}_{\mathrm{OOH}^{*}}+1.5 \times \mathrm{S}_{\mathrm{H} 2}-2 \times \mathrm{S}_{\mathrm{H} 2 \mathrm{O}}-\mathrm{S}_{*}\right)
\end{aligned}
$$

where $E, Z P E$, and S are the total energy, zero-point energy, and entropy of intermediates, respectively.

Electrodepositing of $\mathrm{a}_{-} \mathrm{Ni}_{0.5} \mathrm{Fe}_{0.5}(\mathrm{OH})_{2}$ on foam nickel (NF). The NF $(1 \mathrm{~cm} \times 2 \mathrm{~cm})$ was ultrasonically cleaned with $1 \mathrm{M} \mathrm{HCl}$ solution for 30 min to remove the oxide layer on the surface and then rinsed with deionized water and absolute ethanol for several times, followed by dring at $60^{\circ} \mathrm{C}$ for later use. The a$\mathrm{Ni}_{0.5} \mathrm{Fe}_{0.5}(\mathrm{OH})_{2}$ on NF electrode was prepared by one-step electrochemical deposition (Fig. 1a). The threeelectrode system was employed, the working electrode was the NF electrode to be deposited, the counter electrode was platinum electrode, and the reference electrode was $\mathrm{Ag} / \mathrm{AgCl}$ electrode. The $0.02 \mathrm{M}$ $\mathrm{Ni}\left(\mathrm{NO}_{3}\right)_{2} \cdot 6 \mathrm{H}_{2} \mathrm{O}$ and $0.01 \mathrm{M} \mathrm{Fe}\left(\mathrm{NO}_{3}\right)_{3} \cdot 9 \mathrm{H}_{2} \mathrm{O}$ were used as electroplating solution at a deposition potential of $-1.4 \mathrm{~V}$ vs. $\mathrm{Ag} / \mathrm{AgCl}$ with the deposition charge of $1 \mathrm{C}$. The ratio of $\mathrm{Ni}$ to Fe was determined by adjusting the mole ratio of $\mathrm{Ni}\left(\mathrm{NO}_{3}\right)_{2} \cdot 6 \mathrm{H}_{2} \mathrm{O}$ and $\mathrm{Fe}\left(\mathrm{NO}_{3}\right)_{3} \cdot 9 \mathrm{H}_{2} \mathrm{O}$ in the mixed electroplating solution.

Physical characterizations. The surface microstructure of the sample was tested by the Nova NanoSEM 230 from FEl Company (USA) Scanning Electron Microscope (SEM) with the working voltage at $15 \mathrm{kV}$. The microstructure and high-resolution crystal image were characterized by Tecnai G2 F20 transmission electron microscope (TEM). Before the test, the sample is ultrasonically dispersed in ethanol, and then dropped on the special copper mesh. After being purged and dried by air, it can be tested under vacuum with the acceleration voltage at $15 \mathrm{kV}$. The phase composition was characterized by X-ray diffraction (XRD, Rigaku Ultima III diffractometer, Cu Ka radiation). A Thermo ESCALAB 250 X-ray photoelectron spectrometer (XPS) was employed to analyze the composition and element valence of the samples. The binding energy was calibrated using $\mathrm{C} 1 \mathrm{~s}$ with a binding energy of $284.6 \mathrm{eV}$ as an internal standard. Raman spectra were examined by Horiba T64000@514 nm with an argon ion as laser light source. The electron paramagnetic resonance (EPR) spectra were obtained using a Bruker (Model EMX-10/12 X-band, Bruker, Germany) electron paramagnetic resonance spectrometer at room temperature $\left(25^{\circ} \mathrm{C}\right)$. The settings used were a center field of $2670.0 \mathrm{G}$ for $\mathrm{Ni}_{0.5} \mathrm{Fe}_{0.5}(\mathrm{OH})_{2}$ and $2900 \mathrm{G}$ for $\mathrm{Ni}_{0.5} \mathrm{Fe}_{0.5} \mathrm{O}_{\mathrm{x}} \mathrm{H}_{\mathrm{y}}$, a microwave frequency of $9.84 \mathrm{GHz}$, and a power of $2 \mathrm{~mW}$. The magnetic measurements were carried out on a superconducting quantum interference device (MPMS SQUID XL 7, Quantum Design, USA) with a moment detection limitation of $5 \times 10^{-8} \mathrm{emu}$, a magnetic field strength of $\pm 7 \mathrm{~T}$, and the temperature range of $2-1000 \mathrm{~K}$.

Electrochemical measurements. All electrochemical experiments were performed on Electrochemical Analyzer (CHI 760E) using a standard three-electrode configuration. The working electrode was Ni foam (thickness, $1.8 \mathrm{~mm}$ ) or carbon paper (TGP-H-060, TORAY). The reference electrode was saturated $\mathrm{Ag} / \mathrm{AgCl}$, and the counter electrode was Pt foil. The electrocatalytic performances were tested in $1 \mathrm{M} \mathrm{N}_{2}$ - 
saterated $\mathrm{KOH}$ solution as ambient conditions. All measured potentials in this work were converted to

reversible hydrogen potential (RHE) according to Nernst equation of $\mathrm{E}_{\mathrm{RHE}}=\mathrm{E}_{\mathrm{Ag} / \mathrm{AgCl}}+0.059 \mathrm{pH}+0.197 \mathrm{~V}$. In the heating experiment, the effect of temperature on the reference electrode potential has been deducted, and the correction of temperature coefficient is as shown in Supplementary Fig. 15. Linear sweep voltammetry (LSV) was obtained with the scan rate of $10 \mathrm{mV} \mathrm{s}^{-1}$ with or without iR compensation within the cell. The electrochemical double layer $\left(\mathrm{C}_{\mathrm{dl}}\right)$ were calculated by the non-Faradaic cycle voltammetry at different scan rates. The electrochemical impedance spectra (EIS) were recorded with a frequency range from $100 \mathrm{kHz}$ to $0.01 \mathrm{~Hz}$. The quantitative analysis of $\mathrm{O}_{2}$ and $\mathrm{H}_{2}$ are obtained by using gas chromatograph (GC8890, Agilent Corp., 5A zeolite column and Ar as carrier) to determine the faradaic efficiency. The test was performed in a gas-sealed electrolytic cell using flowing nitrogen to prevent the accumulation of high temperature water vapor. The apparent electrochemical activation energy $\left(Q_{M}\right)$ for $\mathrm{Ni}^{2+} / \mathrm{Ni}^{3+}$ oxidation can be determined using the Arrhenius relationship:

$$
\frac{\partial \log J_{N}}{\partial \frac{1}{T}}-\frac{Q_{N}}{23 .}
$$

where $J_{p}$ is the kinetic peak current for $\mathrm{Ni}^{2+} / \mathrm{Ni}^{3+}$ oxidation, $\mathrm{T}$ is the absolute temperature in Kelvin , and $\mathrm{R}$ is the universal gas constant. From the slope of the Arrhenius plot, the $Q_{M}$ can be extracted.

\section{Declarations}

\section{Acknowledgements}

This work was supported primarily by the National Natural Science Foundation of China (grant nos $51872135,51902137,51972227,51572121,21603098$, and 21633004).

\section{References}

1. Jacobson, M. Z. et al. $100 \%$ clean and renewable wind, water, and sunlight all-sector energy roadmaps for 139 countries of the world. Joule 1, 108-121 (2017).

2. Glenk, G. \& Reichelstein, S. Economics of converting renewable power to hydrogen. Nat. Energy 4, 216-222 (2019).

3. Hosseini, S. E. \& Wahid, M. A. Hydrogen production from renewable and sustainable energy resources: Promising green energy carrier for clean development. Renew. Sust. Energ. Rev. 57, 850866 (2016).

4. Seh, Z. W. et al. Combining theory and experiment in electrocatalysis: Insights into materials design. Science 355, eaad4998 (2017).

5. Suen, N. T. et al. Electrocatalysis for the oxygen evolution reaction: recent development and future perspectives. Chem.Soc.Rev. 46, 337-365 (2017). 
6. Chung, D. Y. et al. Dynamic stability of active sites in hydr(oxy)oxides for the oxygen evolution reaction. Nat. Energy 5, 222-230 (2020).

7. Zhang, B. et al. Homogeneously dispersed multimetal oxygen-evolving catalysts. Science 352, 333337 (2016).

8. Kriechbaum, L. \& Kienberger, T. Optimal municipal energy system design and operation using cumulative exergy consumption minimisation. Energies 13, 182 (2020).

9. Garcés-Pineda, F. A., Blasco-Ahicart, M., Nieto-Castro, D., López, N. \& Galán-Mascarós, J. R. Direct magnetic enhancement of electrocatalytic water oxidation in alkaline media. Nat. Energy 4, 519-525 (2019).

10. Dotan, H. et al. Decoupled hydrogen and oxygen evolution by a two-step electrochemical-chemical cycle for efficient overall water splitting. Nat. Energy 4, 786-795 (2019).

11. Wallace, A. G. \& Symes, M. D. Decoupling strategies in electrochemical water splitting and beyond. Joule 2, 1390-1395 (2018).

12. Rousseau, R., Glezakou, V. A. \& Selloni, A. Theoretical insights into the surface physics and chemistry of redox-active oxides. Nat. Rev. Mater. 5, 460-475 (2020).

13. Torun, E., Fang, C. M., Wijs, G. A. d. \& Groot, R. A. d. Role of magnetism in catalysis: $\mathrm{RuO}_{2}(110)$ surface. J. Phys. Chem. C117, 6353-6357 (2013).

14. Bytautas, L., Matsunaga, N. \& Ruedenberg, K. Accurate ab initio potential energy curve of $\mathrm{O}_{2}$. II. Corevalence correlations, relativistic contributions, and vibration-rotation spectrum. J. Chem. Phys. 132, 074307 (2010).

15. Xiao, H., Shin, H. \& Goddard, W. A. Synergy between Fe and $\mathrm{Ni}$ in the optimal performance of (Ni, $\mathrm{Fe}) \mathrm{OOH}$ catalysts for the oxygen evolution reaction. Proc. Natl. Acad. Sci. U. S. A. 115, 5872-5877 (2018).

16. Sun, Y. M. et al. Spin-related electron transfer and orbital interactions in oxygen electrocatalysis. Adv. Mater. 32, 2003297 (2020).

17. Li, X. N., Cheng, Z. X. \& Wang, X. L. Understanding the mechanism of the oxygen evolution reaction with consideration of spin. Electrochem. Energy Rev. 4, 136-145 (2021).

18. Song, J. J. et al. A review on fundamentals for designing oxygen evolution electrocatalysts. Chem. Soc. Rev. 49, 2196-2214 (2020).

19. Gorlin, M. et al. Oxygen evolution reaction dynamics, faradaic charge efficiency, and the active metal redox states of Ni-Fe oxide water splitting electrocatalysts. J. Am. Chem. Soc. 138, 5603-5614 (2016).

20. Mansour, A. N. \& Melendres, C. A. Characterization of slightly hydrated $\mathrm{Ni}(\mathrm{OH})_{2}$ by XPS. Surf. Sci. Spectra 3, 247-254 (1994).

21. Mcintyre, N. S. \& Zetaruk, D. G. X-ray photoelectron spectroscopic studies of iron oxides. Anal. Chem. 49, 1521-1529 (1977). 
22. Lo, Y. L. \& Hwang, B. J. In situ raman studies on cathodically deposited nickel hydroxide films and electroless NiP electrodes in 1 M KOH solution. Langmuir 14, 944-950 (1998).

23. Nieuwoudt, M. K., Comins, J. D. \& Cukrowski, I. The growth of the passive film on iron in $0.05 \mathrm{M}$ $\mathrm{NaOH}$ studied in situ by Raman micro-spectroscopy and electrochemical polarisation. Part I: nearresonance enhancement of the Raman spectra of iron oxide and oxyhydroxide compounds. $J$. Raman Spectrosc. 42, 1335-1339 (2011).

24. Mary W. Louie \& Bell, A. T. An investigation of thin-film Ni-Fe oxide catalysts for the electrochemical evolution of oxygen. J. Am. Chem. Soc. 135, 12329-12337 (2013).

25. Li, N. et al. Influence of iron doping on tetravalent nickel content in catalytic oxygen evolving films. Proc. Natl. Acad. Sci. U. S. A. 114, 1486-1491 (2017).

26. Trzesniewski, B. J. et al. In situ observation of active oxygen species in Fe-containing Ni-based oxygen evolution catalysts: The effect of pH on electrochemical activity. J. Am. Chem. Soc. 137, 15112-15121 (2015).

27. Ahn, H. S. \& Bard, A. J. Surface interrogation scanning electrochemical microscopy of $\mathrm{Ni}_{1-x} \mathrm{Fe}_{x} \mathrm{OOH}(0$ $<x<0.27)$ oxygen evolving catalyst: kinetics of the "fast" iron sites. J. Am. Chem. Soc. 138, 313-318 (2016).

28. Stevens, M. B., Cdm, T., Enman, L. J., Deng, J. \& Boettcher, S. W. Reactive Fe-sites in Ni/Fe (oxy)hydroxide are responsible for exceptional oxygen electrocatalysis activity. J. Am. Chem. Soc. 139, 11361-11364 (2017).

29. Lee, S., Bai, L. \& Hu, X. Deciphering iron-dependent activity in oxygen evolution catalyzed by nickeliron layered double hydroxide. Angew. Chem., Int. Ed. 59, 8072-8077 (2020).

30. Chen, J. Y. C. et al. Operando analysis of NiFe and Fe oxyhydroxide electrocatalysts for water oxidation: detection of $\mathrm{Fe}^{4+}$ by mössbauer spectroscopy. J. Am. Chem. Soc. 137, 15090-15093 (2015).

31. Lipscomb, J. D. Electron paramagnetic resonance detectable states of cytochrome P-450 cam. Biochemistry 19, 3590-3599 (1980).

32. Cairns, R. W. \& Ott, E. X-ray studies of the system nickel-oxygen-water. I. Nickelous oxide and hydroxide. J. Am. Chem. Soc. 55, 527-533 (1933).

33. Van der Ven, A., Morgan, D., Meng, Y. S. \& Ceder, G. Phase stability of nickel hydroxides and oxyhydroxides. J. Electrochem. Soc. 153, A210-A215 (2006).

34. Kresse, G. G. \& Furthmüller, J. J. Efficient iterative schemes for ab initio total-energy calculations using a plane-wave basis set. Phys. Rev. B 54, 11169-11186 (1996).

35. Grimme, S. Semiempirical GGA-type density functional constructed with a long-range dispersion correction. J. Comput. Chem. 27, 1787-1799 (2006).

\section{Figures}




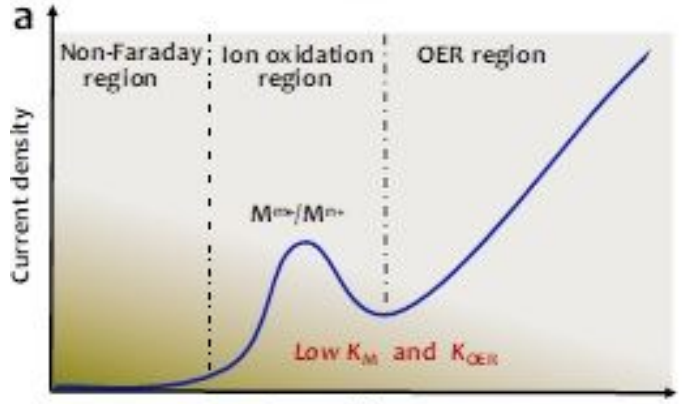

Potential

C

Limit of $K_{m}:$ proton coupled spin-related electron transfer

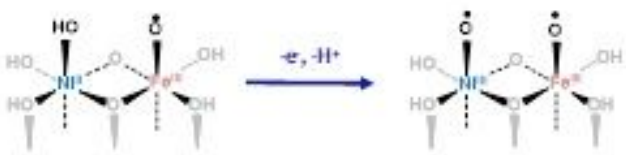

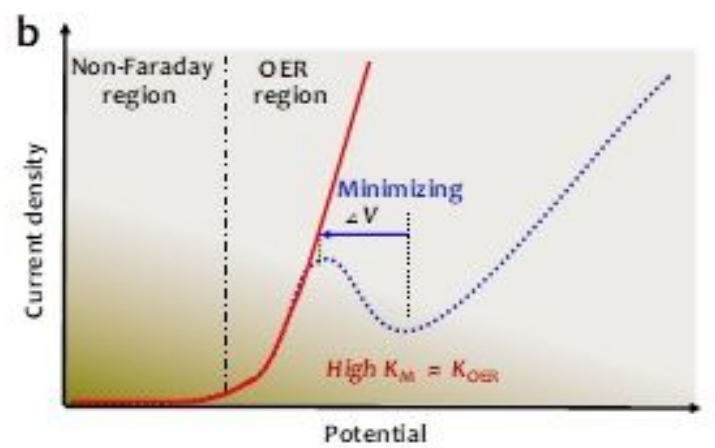

$\mathrm{d}_{\text {Limit of } K_{\alpha \in S} \text { proton coupled spin-related electron transfer }}$

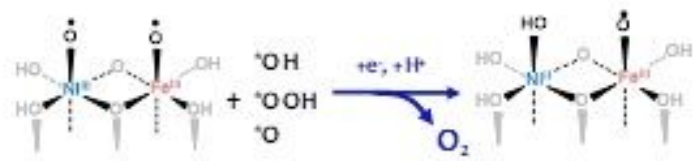

\section{Figure 1}

The main kinetic obstacles in redox couple mediated water splitting. a,Typical current-voltage curve of OER on redox-mediated catalysts. KM: oxidation rate constant of redox couple; KOER: OER rate constant. b, An ideal situation is that the onset of OER started at the oxidation potential of redox couple, resulting from minimizing the $\Delta \mathrm{V}$ by accelerating the $\mathrm{KM}$ and KOER to nearly same rate. $\mathrm{c}$, The limit of $\mathrm{KM}$ originates from the proton-coupled spin-related electron transfer (PCSRET) during the oxidation of hydroxides/oxyhydroxides redox couple. $d$, The limit of KOER results from the PCSRET during evolution of OER intermediates $\left({ }^{\star} \mathrm{OH},{ }^{\star} \mathrm{O},{ }^{\star} \mathrm{OOH}\right)$.
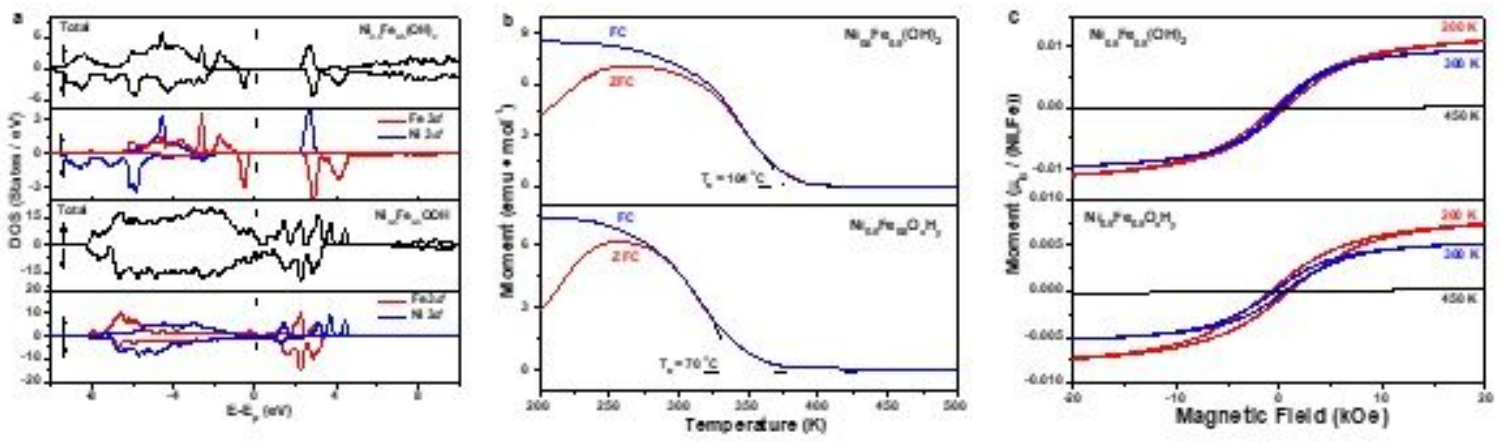

\section{Figure 2}

The magnetic properties of $\mathrm{Ni0} .5 \mathrm{Fe} 0.5(\mathrm{OH}) 2$ and Ni0.5Fe0.50xHy. a,Total DOS and projected DOS. b, ZFC and FC magnetizations as a function of temperature with applied magnetic field $\mathrm{H}=500$ Oe. $\mathrm{c}, \mathrm{M}-\mathrm{H}$ loops. 

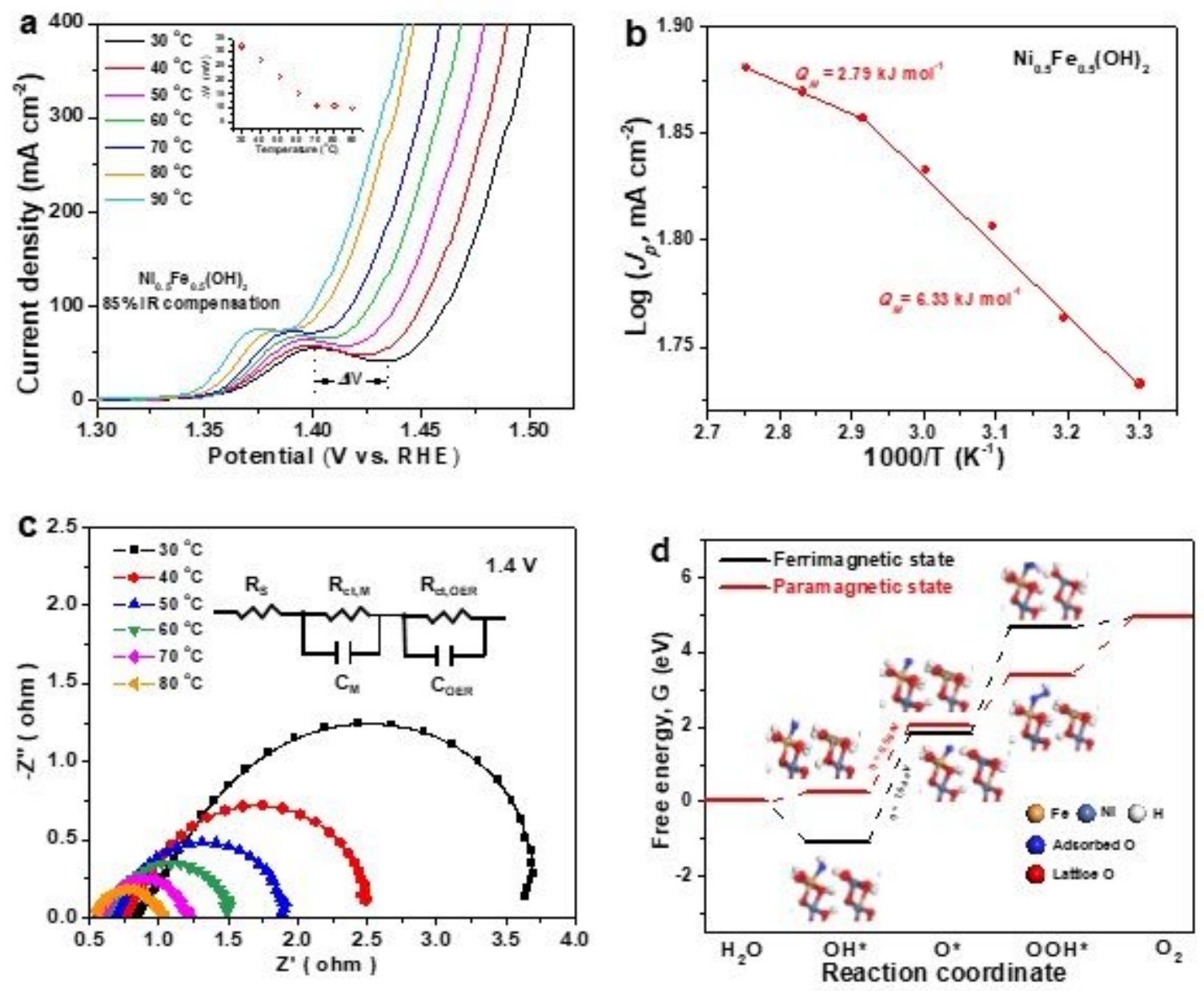

\section{Figure 3}

The heat-electricity coupling electrochemical kinetics for $\mathrm{Ni0} .5 \mathrm{Fe} 0.5(\mathrm{OH}) 2$ at $30-90 \mathrm{oC}$. a, The temperature-dependent OER polarization curves at a scan rate of $10 \mathrm{mV} \mathrm{s}-1$. Inset shows the temperaturedependent $\Delta \mathrm{V}$ with a sharp decrease at $\mathrm{T}>\mathrm{TN}$. $\mathrm{b}$, Arrhenius plot of inverse temperature versus log of $\mathrm{Ni2}+/ \mathrm{Ni3}+$ oxidation peak current. c, The temperature-dependent EIS spectra at $1.4 \mathrm{~V}$. d, Free energy diagram for ferrimagnetic and paramagnetic $\mathrm{Ni} 0.5 \mathrm{Fe} 0.5 \mathrm{OOH}$ models, with calculated structures and ratedetermining steps.
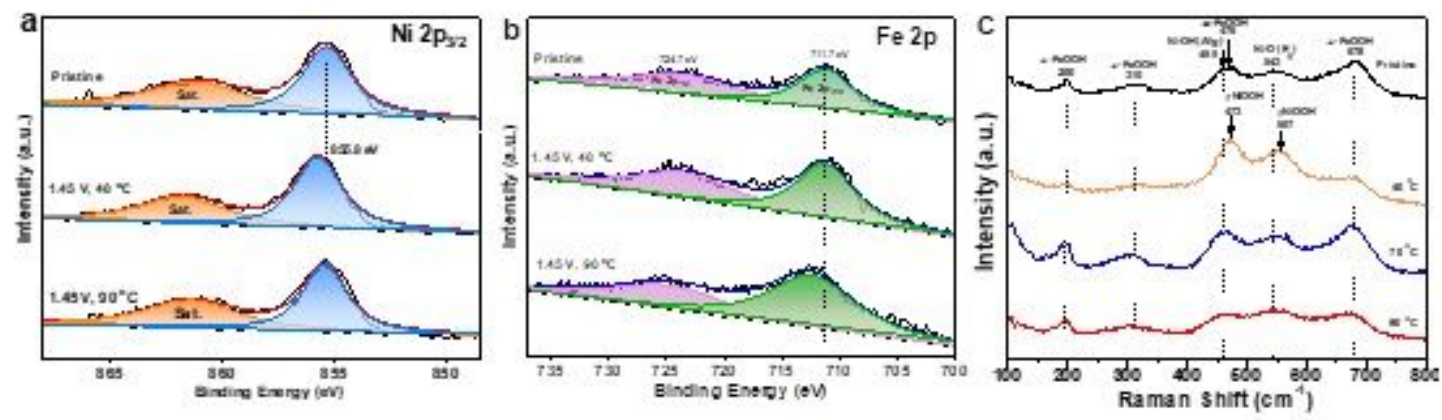

Figure 4 
Spectroscopic evidences to Ni2+/Ni3+ kinetics. a and b, High-revolution XPS spectra of Ni 2p and Fe 2p for $\mathrm{Ni0} .5 \mathrm{Fe} 0.5(\mathrm{OH}) 2$ at different potentials and temperatures. c, Raman spectra for $\mathrm{Ni0.5Fe0.5(OH)2}$ without and with applied potentials at $1.45 \mathrm{~V}$ at 40 oC, 70 oC, and $90 \mathrm{oC}$.
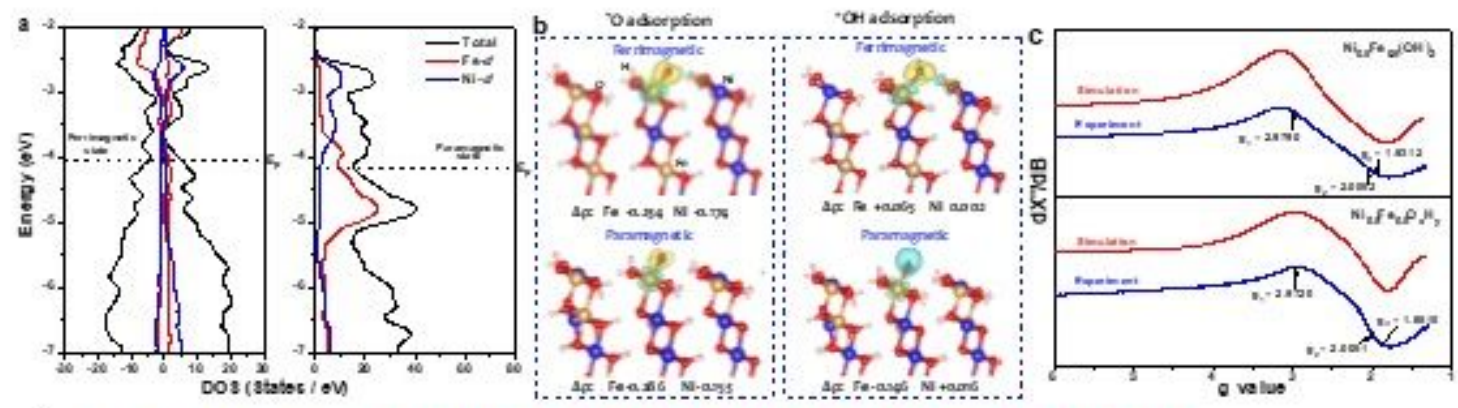

d Nature of high $K_{\text {oe R }}$ : Low-spin $\mathrm{Fe}^{3 \cdot}$ increasing the electron transfer pathway
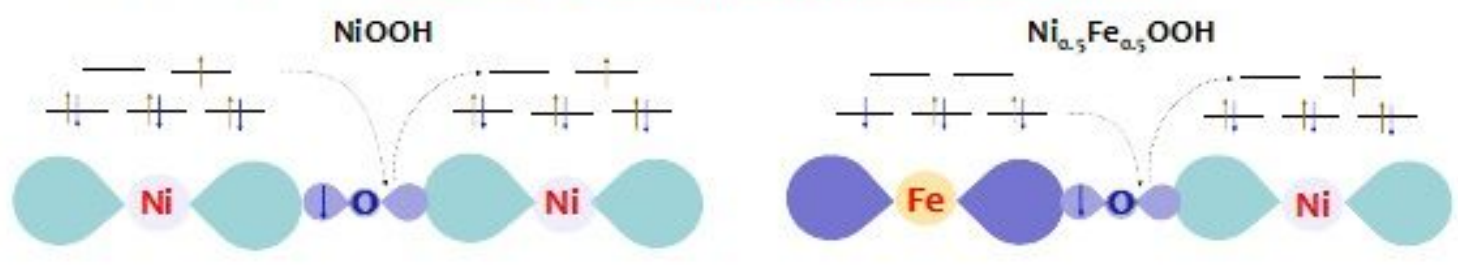

e Accelarating $K_{\mathrm{M}}$ : Heat coupling to electron spin

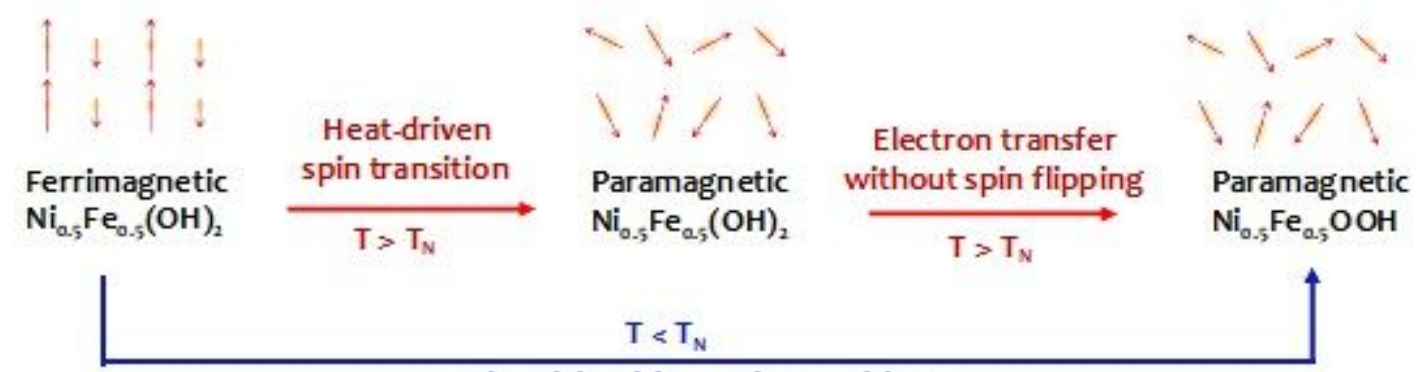

Electricity-driven spin transition

\section{Figure 5}

Nature of high OER activity and physical basis of heat-electricity coupling. a Fermi level EF, referring to the vacuum level, for ferrimagnetic and paramagnetic $\mathrm{Ni0} .5 \mathrm{Fe} 0.5 \mathrm{OOH}$. b, Charge density difference for ${ }^{*} \mathrm{OH}$ and ${ }^{*} \mathrm{O}$ species adsorbed on the ferrimagnetic and paramagnetic $\mathrm{Ni} 0.5 \mathrm{Fe} 0.5 \mathrm{OOH}$. The yellow and green charge densities correspond to charge accumulation and depletion, respectively. The electron transfer number $(\Delta \rho)$ was obtained by Bader charge analysis. The + and - indicate gaining electrons and losing electrons, respectively. c, Experimental and simulated EPR spectra for $\mathrm{Ni0} .5 \mathrm{Fe} 0.5(\mathrm{OH}) 2$ and Ni0.5Fe0.50xHy. d, Low-spin Fe3+ significantly enlarging the PCSRET of OER by increasing the electron transfer pathway. e, Heat coupling to promote PCSRET of Ni2+/Ni3+ oxidation via heat-driven magnetic transition.

\section{Supplementary Files}

This is a list of supplementary files associated with this preprint. Click to download. 
- Supplementarylnformation.docm

Page 16/16 